\title{
Role of Polymer Interactions with Clays and Modifiers on Nanomechanical Properties and Crystallinity in Polymer Clay Nanocomposites
}

\author{
Dinesh R. Katti, Kalpana S. Katti, M. Raviprasad, and Chunju Gu \\ Department of Civil Engineering, North Dakota State University, Fargo, ND 58108, USA \\ Correspondence should be addressed to Dinesh R. Katti, Dinesh.Katti@ndsu.edu
}

Received 20 January 2012; Revised 10 April 2012; Accepted 11 April 2012

Academic Editor: Sevan P. Davtyan

Copyright () 2012 Dinesh R. Katti et al. This is an open access article distributed under the Creative Commons Attribution License, which permits unrestricted use, distribution, and reproduction in any medium, provided the original work is properly cited.

\begin{abstract}
We present the effect of organic modifier on crystallinity and nanomechanical properties of polymer clay nanocomposites (PCNs) using two different polymers while maintaining the same nanoclay and organic modifier. Experimental results and interaction energy maps of Polybutylene-Terephthalate- (PBT-) PCN system indicate that the underlying mechanisms of change in crystallinity and improvement in mechanical properties as proposed in altered phase theory are valid. Experimental and molecular simulation studies of PBT-PCN and Nylon6-PCN reveal that a higher crystallinity polymer could require significantly higher attractive and repulsive interaction energies between polymer and organic modifiers to change the crystallinity of the polymer in the PCN significantly and thus improve mechanical properties of the PCN.
\end{abstract}

\section{Introduction}

Polymer clay nanocomposites (PCNs) are widely researched material systems for wide variety of applications in industry because of enhanced mechanical, thermal, optical, and barrier properties. PCNs are categorized as intercalated or exfoliated and are typically synthesized by adding small amount (about 1-9\% of weight polymer) [1,2] of organically modified nanosized expansive clay. Addition of organically modified clay enhances the mechanical properties [3], thermal properties [4-6], and barrier properties [4, 69] of polymer clay nanocomposites. Most importantly, the amount of clay in PCN influences the crystallinity of polymer and the mechanical properties [10]. Studies show that the properties of PCNs depend on individual phases and interaction between individual constituents $[10$ 12]. Our previous work on PCNs has shown that the nonbonded interactions between different constituents alter the polymer phase [10-12] and thus significantly influence the mechanical properties of PCNs [1]. The organic modifier, which is used to modify the clay, has a significant influence on crystallinity of polymer and elastic modulus of PCNs
[11]. Effect of different organic modifiers, which contain different functional groups and different chain lengths, is studied with Nylon6 in detail [11] and the results indicate that the functional group and backbone chain length of organic modifier have a significant influence on $d$-spacing of PCNs, crystallinity of polymer, and the elastic modulus of PCNs. In this paper, we present the results of experimental and quantitative modeling studies on PCN with two different polymers, Nylon6 and Polybutylene Terephthalate (PBT), and same organic modifier, and nano clay.

PBT is a semicrystalline thermoplastic polymer which shows excellent properties such as rate of crystallization, thermal stability and processability [13]. PBT has been used widely in nanocomposites [14-17] and shows improved tensile modulus and strength [17], enhanced thermo mechanical properties and elastic modulus [6]. High viscosity PBT nanocomposites show improved mechanical, dynamic mechanical properties [16]. Several experimental studies conducted on PBT clay nanocomposites can be found in the literature [6, 13-23]. In this paper, PCN containing Nylon6 is referred to as Nylon6-PCN and the PCN containing PBT is referred to as PBT-PCN. Properties of Nylon6-PCN are 
studied at the molecular scale using molecular dynamics and experiments [10-12, 24-28]. Experimental results of Nylon6-PCN used in the discussion is from our previous work [10]. Molecular dynamics simulations provide an insight into mechanisms responsible for the enhancement of PCN properties. Molecular models are designed to be close to experimental condition and models are validated with experimental $d$-spacing. Quantitative interaction energies between PBT-PCN constituents are calculated and the results are compared quantitatively with Nylon6-PCN. Crystallinity and elastic modulus tests are conducted using differential scanning calorimetry (DSC) and nanoindentation technique, respectively. This paper describes a comprehensive quantitative study of interaction energies and the effect of interactions on properties of polymer clay nanocomposites.

\section{Materials and Methods}

2.1. Materials. Na-montmorillonite with cationic exchange capacity of 76.4 mequiv/100 g was obtained from the Clay Minerals Repository at the University of Missouri, Columbia, $\mathrm{MO}$, USA. 12-Aminolauric acid $\left[\mathrm{NH}_{2}\left(\mathrm{CH}_{2}\right)_{11} \mathrm{COOH}\right]$ was supplied by the TCI America. $\operatorname{Poly}(1,4$-butylene terephthalate) $(M v=38,000)$ was obtained from the SigmaAldrich, Inc., USA. Polyamide 6 (PA6) [(CH2)5CONH]n $(M v=16000)$ was supplied by the Polysciences, Inc., USA. Trifluoroacetic acid (99.9\%) and chloroform (99.97\%) were purchased from the EMD chemicals Inc, Germany. Methanol anhydrous (99.9\%), formic acid (97\%), silver nitrate, standard volumetric solution, and hydrochloric acid $(\mathrm{HCl})$ were purchased from the Alfa Aesar, MA, USA.

\subsection{Preparation of Organically Modified Montmorillonite} (OMMT). Ten grams of Na-montmorillonite (Na-MMT) are crushed into fine powder and screened through \#325 sieve $(45 \mu \mathrm{m})$ and then dispersed into deionized (DI) preheated $(333 \mathrm{~K})$ water ( $400 \mathrm{~mL}$ for PBT, $200 \mathrm{~mL}$ for PA6). The clay solution is stirred vigorously for 1 hour to disperse the clay uniformly and swell sufficiently. $3.312 \mathrm{~g}$ ( $15.4 \mathrm{mmol})$ of 12-aminolauric acid and $2.5 \mathrm{~mL}$ of $0.1 \mathrm{~N} \mathrm{HCl}$ are dissolved in DI water at $333 \mathrm{~K}$ and stirred vigorously to form a uniform solution. The clay suspension is gradually added into the acid solution and is stirred vigorously at $333 \mathrm{~K}$ for 1 hour to obtain the organically modified montmorillonite (OMMT). Prepared OMMT is washed several times with DI water to completely remove $\mathrm{Cl}^{-}$and then the solution is tested by $0.1 \mathrm{~N} \mathrm{AgNO}_{3}$ to verify the absence of $\mathrm{Cl}^{-}$ions. Finally, the OMMT cake is dried in an oven at $333 \mathrm{~K}$ for 24 hours and then ground and screened through \#325 sieve for synthesis of PCN.

2.3. Preparation of PBT Film and PBT-Clay Nanocomposite (PBT-PCN) Film. Five grams of PBT are added to $42 \mathrm{ml}$ chloroform and $7 \mathrm{~mL}$ trifluoroacetic acid (TFA) and stirred for 2 hours to make a uniform solution. Subsequently, $0.45 \mathrm{~g}$ ( $9 \mathrm{wt} \%$ of OMMT with respect to pure PBT) OMMT is added to the PBT- $\mathrm{CHCl}_{3}$-TFA solution and then stirred vigorously for 3 hours to obtain PBT-PCN. PBT and PBT-PCN films are obtained by casting the corresponding solutions on a glass slide using a drawdown bar (Paul N. Gardner Company, Inc.) set at 25 mils thickness.

2.4. Preparation of Nylon6-Clay Nanocomposite (Nylon6$P C N$ ). Ten grams of Nylon6 are added to $155.73 \mathrm{ml}$ formic acid (FA) and stirred vigorously for 40 minutes to prepare a uniform solution. Next, $0.9 \mathrm{~g}$ ( $9 \mathrm{wt} \%$ of OMMT with respect to pure nylon6) of OMMT is dispersed into the nylon6FA solution and stirred vigorously for 6 hours at room temperature. DI water is added to the resulting solution to form PCN and to remove the FA from PCN. Finally, the remaining DI water is removed by adding methanol anhydrous and the resulting solution is placed in a vacuum oven set at $313 \mathrm{~K}$ temperature for a period of 24 hours to obtain the PCN.

\subsection{Characterization}

2.5.1. XRD Characterization. The X-ray analysis is performed by X-ray diffractometer (Philips Analatical X'pert MPD, Almelo, Netherlands) with secondary monochromator and $\mathrm{Cu}$-tube by $\mathrm{CuK} \alpha$ radiation wavelength of $1.5406 \AA$. $\mathrm{X}$-ray diffraction of MMT and OMMT is conducted at a scan rate of $0.01^{\circ} \mathrm{s}$ in each case and with scan range of $2 \theta=$ $2.07-35.02^{\circ}$ for MMT and $2 \theta=2.11-35.06^{\circ}$ for OMMT. The same OMMT was used to prepare PBT-PCN and nylon6PCN. For the PBT-PCN film a scan rate of $0.02^{\circ} / \mathrm{s}$ and the scan range of $2 \theta=2.03-65.01^{\circ}$ are used. The Nylon6-PCN is compressed into thin sheets by compression testing machine (SATEC, model 22 EMF, PA, USA) and the X-ray diffraction of Nylon6-PCN was done at a scan rate of $4^{\circ} / \mathrm{min}$ with the scan range of $2 \theta=2.01-15^{\circ}$.

2.5.2. Photoacoustic- (PA-)FTIR Characterization. PA-FTIR experiments are conducted in FTIR bench (model Nexus, Thermo Nicolet, USA) with a photoacoustic cell (MTEC Photoacoustics model no. 300). Sample is prepared by pressing the OMMT powder into a pellet. The nylon6 sample is heated gradually from $303 \mathrm{~K}$ to $493 \mathrm{~K}$ and then pressed into a pellet. The PBT and PBT-PCN samples are prepared in smaller size and placed in the sample holder. The PA-FTIR is conducted in the linear photoacoustic mode for 500 scans at a resolution of $4 \mathrm{~cm}^{-1}$, with moving mirror velocity of $0.1581 \mathrm{~cm} / \mathrm{s}$. FTIR data are acquired from 400 to $4000 \mathrm{~cm}^{-1}$.

2.5.3. Differential Scanning Calorimetry (DSC). DSC experiments are conducted using differential scanning calorimeter (model Q1000 DSC) of TA instruments, New Castle, Delaware, USA. PBT and PBT-PCN samples are heated from $25^{\circ} \mathrm{C}$ to $250^{\circ} \mathrm{C}$ with nitrogen atmosphere with the heating rate of $10^{\circ} \mathrm{C} / \mathrm{min}$ for heating/cooling/heating cycle with retention time of 3 minutes at the end of each treatment for temperature equilibration. Nylon6 and Nylon6-PCN samples are heated from $30^{\circ} \mathrm{C}$ to $100^{\circ} \mathrm{C}$ in 3 minutes and the temperature is maintained at $100^{\circ} \mathrm{C}$ for 10 minutes. A heating rate of $10^{\circ} \mathrm{C} / \mathrm{min}$ is used for the first heating and cooling cycles with retention time of 10 minutes at $250^{\circ} \mathrm{C}$ and the heating rate of $20^{\circ} \mathrm{C} / \mathrm{min}$ [11] is used in the final heating cycle. We have taken the net weight of 
the respective polymers into consideration. The enthalpy of fusion was determined by integrating the area under the DSC endotherm peak which was divided by the net weight of the material. The percentage of crystallinity $X_{c}$ is determined from DSC measurements by

$$
X_{c}=\frac{\Delta H_{m}}{\Delta H_{m}^{\circ}} 100 \%,
$$

where $\Delta H$ is melting enthalpy of sample $[\mathrm{J} / \mathrm{g}] ; \Delta H_{m}^{\circ}$ represents theoretical value of enthalpy for $100 \%$ crystalline polymer. For PBT homopolymer, $\Delta H_{m}^{\circ}=141 \mathrm{~J} / \mathrm{g}$ [29]; for nylon6, $\Delta H_{m}^{\circ}=203 \mathrm{~J} / \mathrm{g}$ [11]. This is generally considered a standard method to measure crystallinity of polymer which has been described earlier [30] and extensively used in literature $[10,29,31,32]$.

2.5.4. Nanoindentation. Nanoindentation experiments are conducted using triboscope nanoindenter (Hysitron Inc., Minneapolis, MN). The triboscope is operated in association with a multimode AFM controlled by the nanoscope IIIa controller and with the J-type piezo scanner from Veeco (Veeco Metrology Group, Santa Barbara, CA). For PBT and PBT-PCN, load controlled nanoindentation tests are performed using a 100-200 nm Berkovich (three-sided pyramid) diamond indenter tip. Experiments are conducted for maximum load of $2900 \mu \mathrm{N}$. The reduced elastic modulus $\left(E_{r}\right)$ and hardness $(H)$ values are calculated from initial part of the unloading curve using Oliver-Pharr method [33]. The average $E_{r}$ and $H$ are obtained from 30 numbers of indentations for each specimen. For nylon6 and Nylon6PCN, load controlled nanoindentation tests are performed [11]. The elastic modulus is calculated using the following equation:

$$
\frac{1}{E_{r}}=\frac{1-v^{2}}{E}+\frac{1-v_{i}^{2}}{E_{i}},
$$

where $E$ and $v$ are the elastic modulus and Poisson's ratio of the sample respectively. $E_{i}$ and $v_{i}$ are the elastic modulus and Poisson's ratio for the diamond indenter. In the case of polymeric materials and its composites, due to the fact that $E_{i} \gg E$, (2) can be simply given as [34]

$$
E=E_{r}\left(1-v^{2}\right)
$$

2.6. Simulations Using Molecular Dynamics. Molecular dynamics (MD) is a computational method used to study the position and interaction of atoms and molecules. MD is used extensively to study proteins, bio molecules, polymers, and minerals. MD provides a good understanding of molecules with respect to their interactions and molecular structure. This method involves solving the equation of motion in small time steps. The equation of motion is $F_{i}=m_{i} a_{i}$, where $F_{i}$ is the force acting on an atom $i, m_{i}$ is the mass of an atom $i$, and $a_{i}$ is the acceleration of an atom $i$. Change in energy of an atom $i$ with respect to its position $(r)$ is equal to the force acting on an atom $i$. By solving these equations of motion, MD provides time-dependent response for the molecular system. This response contains position of every atom in the system and their velocities. In this work, MD has been used to study the interactions between atoms and group of atoms in PBT-PCN and Nylon6-PCN.

2.6.1. Force Field Parameters for PBT, Nylon6, and Na-MMT. Force field describes the potential energy of a molecular system. Potential energy of any molecular system consists of bonded energy and nonbonded energy. Bonded energy consists of bond, angle, dihedral, and improper energy of the molecular system. Nonbonded energy consists of van der Waals and electro static energy of the molecular system. Total potential energy of the molecular system can be described by the following expression $E_{\text {total }}=\left[E_{\text {bond }}+\right.$ $\left.E_{\text {angle }}+E_{\text {dihedral }}+E_{\text {improper }}\right]+\left[E_{\mathrm{van}}+E_{\text {elec }}\right]$. These individual potential energy terms can be described by mathematical functions and the functions depend on force constants and variables. Some of the general force fields used by researchers are CHARMM, CFF, AMBER, and COMPASS. In our previous work, CHARMM [41] (Chemistry at HARvard Macromolecular Mechanics) force field parameters were used for Polyamide6 and 12-Aminolauric acid and the same set of parameters were used in the present work. We have transformed CFF force field parameters of sodium Montmorillonite to CHARMM force field parameters [4244]. Force field parameters for PBT were obtained by considering number of methyl group and model components which are similar to polyethylene terephthalate [45].

2.6.2. Molecular Model Construction and Simulations. Materials Studio software, developed by Accelrys Software Inc, is used to build the molecular models. This software is widely used to construct molecular models. NAMD2.5b2 [46] and VMD1.8.7 [47] are used to conduct simulations of OMMT, PBT, Nylon6, and PCNs and visualize the results from simulation, respectively. These programs are developed by Theoretical Biophysics Group at Illinois Beckman Institute and widely used by researchers to study complex molecular system.

Organically Modified Montmorillonite (OMMT) Model. OMMT model consists of two sheets of montmorillonite (MMT) and eighteen numbers of 12-aminolauric acid molecules. Size of the OMMT model is $31.68 \AA$ in $X$ direction, $27.44 \AA$ in $Y$ direction, and $24.16 \AA$ in $Z$ direction. Each montmorillonite sheet consists of eighteen unit cells where six unit cells are in $X$ direction and three unit cells are in $Y$ direction. Each of these MMT sheets has nine negative net charges and sheets are placed at $17.60 \AA$ initial $d$-spacing. In our previous work [26], we have studied different initial $d$-spacing and we found that $17.60 \AA$ initial $d$ spacing model provides closest experimental $d$-spacing at the end of simulation. In order to make OMMT model charge neutral, eighteen numbers of 12 -aminolauric acid chains are inserted in the model where nine are inserted in between two MMT sheets and nine are inserted above the MMT sheet as shown in Figure 1. Previous work [25] showed that these 12 -aminolauric acid molecules should be placed flat and parallel to the MMT sheet. Partial charges and structure of 12-aminolauric acid are shown in Figure 2(a). 


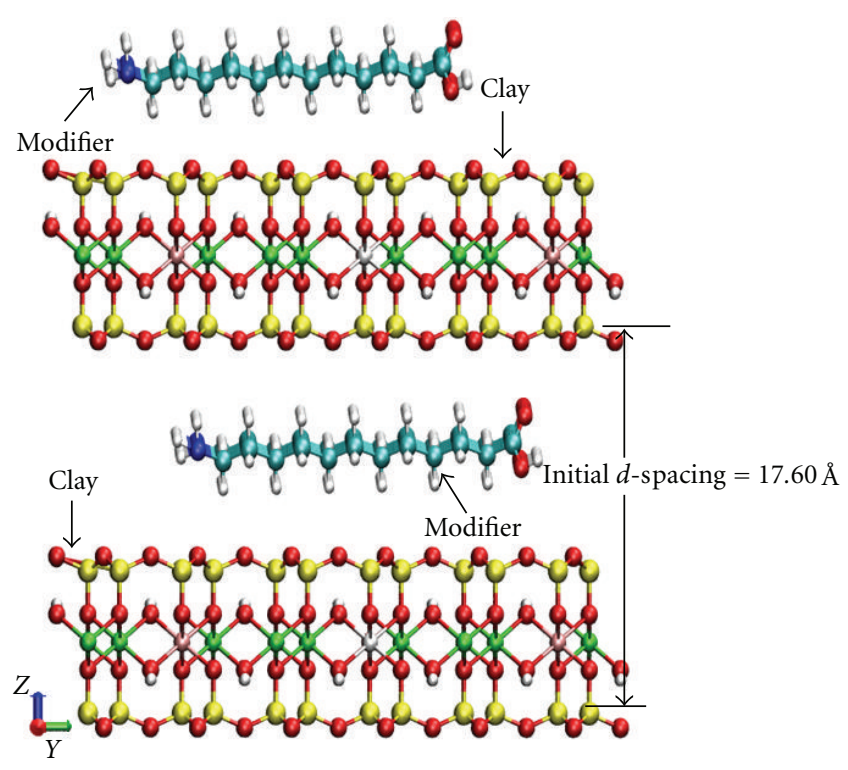

FIGURE 1: Initial OMMT model.

Polybutylene Terephthalate (PBT) Model. PBT monomers are used to build polymers. A representative molecular model of PBT is shown in Figure 3. Six different lengths of PBT polymers were built to study the length effect of polymers on $d$-spacing of clay in PCN. These polymer chains contain two, four, six, eight, ten, and twelve monomers. All PBT polymers were annealed at $700 \mathrm{~K}$ under atmospheric pressure. Annealing process was conducted three times to obtain globally minimized confirmation of PBT chains and minimization was confirmed from the potential energy.

2.6.3. Simulation of OMMT. Initial OMMT model is minimized for 25 ps at a temperature of zero Kelvin in vacuum using molecular dynamics program NAMD. Next, the temperature of the OMMT system is raised to $300 \mathrm{~K}$ in three equal steps by Langevin temperature parameter. Once the temperature is increased to $300 \mathrm{~K}$, pressure of the OMMT system is increased to 1.01325 bars in four equal steps by Langevin piston pressure control. Next, the system temperature is increased by $33 \mathrm{~K}$ and subsequently reduced to atmospheric temperature. The increase and reduction of temperature is done to mimic the experimental conditions as mentioned in Section 2.2. A $0.5 \mathrm{fs}$ time step is used for all OMMT simulations. Finally, OMMT model is simulated for $100 \mathrm{ps}$ at room temperature and pressure with periodic boundary condition. During OMMT simulation, constraints were applied to MMT atoms in $X$ and $Y$ direction but MMT atoms are allowed to move in $Z$ direction. There are no constraints applied to organic modifiers thus organic modifier atoms are allowed to move in all three directions. Simulation of OMMT is done under constant number of particles, constant pressure, and constant temperature (NPT). $16 \AA$ cut-off distance and $14 \AA$ switch distance are used for van der waals and electrostatic energy calculation in all simulations.
2.6.4. Polymer Clay Nanocomposites (PCN) Models. Selected OMMT model, as shown in Figure 4, and minimized PBT models are used to construct PCN models. Six different lengths of PBT chains are used in PCN to select the suitable PCN system. One of the initial PCN models is shown in Figure 5. The suitable PCN system is selected based on experimental $d$-spacing as shown in Figure 6. The estimated mass of PBT chains in PCN model with respect to clay is shown in Table 1. Two PBT chains are inserted into the OMMT model and one is placed in between clay sheets and the other is placed above top clay sheet to ensure the periodic boundary condition during the simulation. Physical dimensions of PBT are measured and compared with the simulated interlayer spacing of OMMT to make sure that the PBT chain fits in the model. The same conditions described above were implemented to construct the nylon6 PCN model. The number of Nylon6 chains in PCN models is selected based on our previous work [11]. Initial and final Nylon6-PCN model are shown in Figures 7 , and 8 respectively. Final model is selected based on the experimental $d$-spacing.

2.6.5. Simulation of PCNs. Molecular simulation of PCN is conducted for PBT-PCN and Nylon6-PCN system. Procedure for minimization and dynamics of PCNs is done as described in Section 2.6.3 Cell basis vector for PCNs is adjusted according to the physical size of different models. Periodic boundary conditions are applied to calculate the electrostatic interactions between PCN constituents. Initially, PCN models are simulated for 25 ps. Based on $d$-spacing, final PCN model is selected and then the final simulation is conducted for 200 ps. Constraints are applied to MMT as mentioned in Section 2.6.3 and polymers are allowed to move freely in all three directions. Constant number, pressure, and temperature (NPT) are used for all PCN simulation. Constant pressure is maintained by Nose'-Hoover Langevin piston pressure control method. This method is used with Langevin dynamics, such as temperature control, in order to perform NPT ensemble. Equilibrium of PCN system is confirmed from the plot of total energy of the system versus simulation time and it is found that 200 ps simulation time is sufficient for the PCN simulations.

\section{Results and Discussion}

\subsection{Experiments}

3.1.1. XRD Results. $d$-spacing of MMT, OMMT, and PCN from several samples are summarized in Table 2. MMT $d$ spacing is less than the OMMT $d$-spacing thus indicating that the organic modifier has intercalated the clay. $d$-spacing of both PCNs lie in between pure MMT $d$-spacing and OMMT $d$-spacing. Intercalation of nylon6 with clay was verified from the XRD, spectroscopic, and simulation studies [26, 27]. PBT-PCN has intercalated structure which has higher $d$ spacing than nylon6-PCN. The reduction of $d$-spacing in PCN compared to OMMT might be caused by dissolution of the modifier in the solvents. 


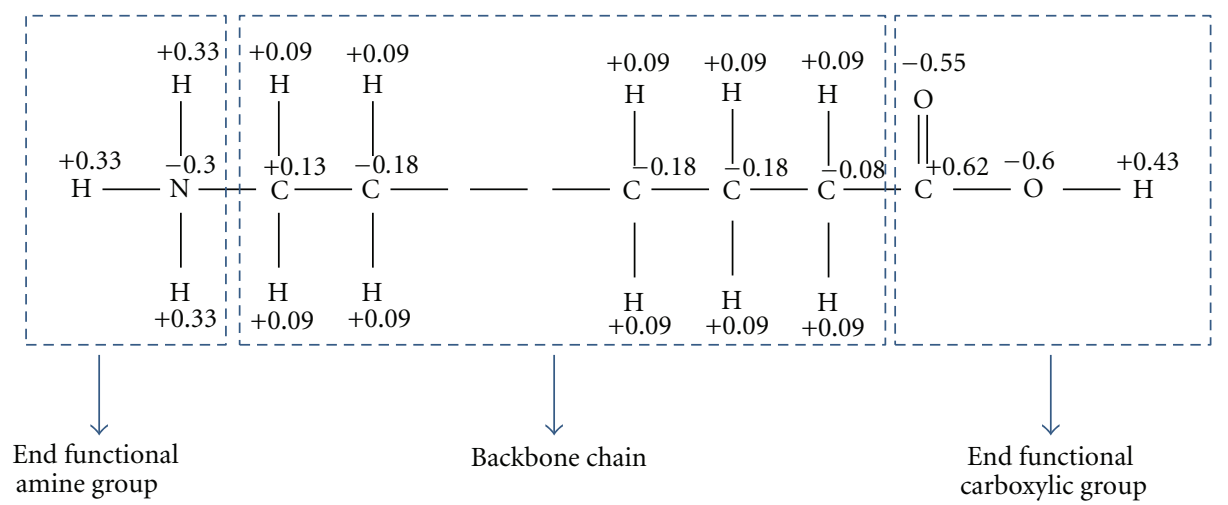

(a)

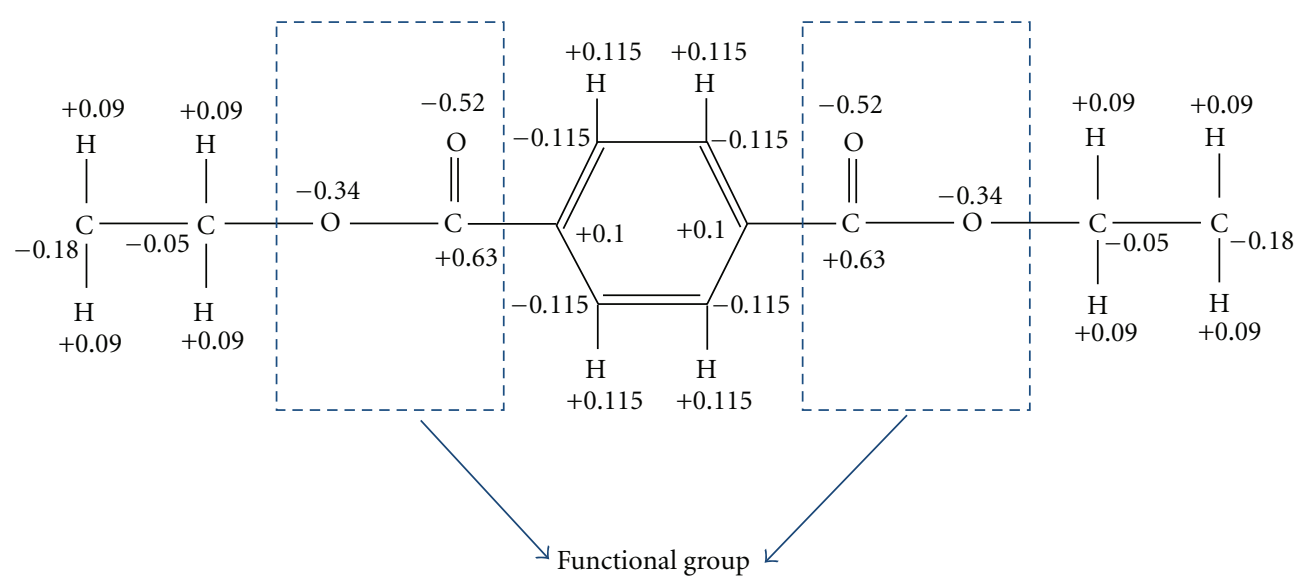

(b)

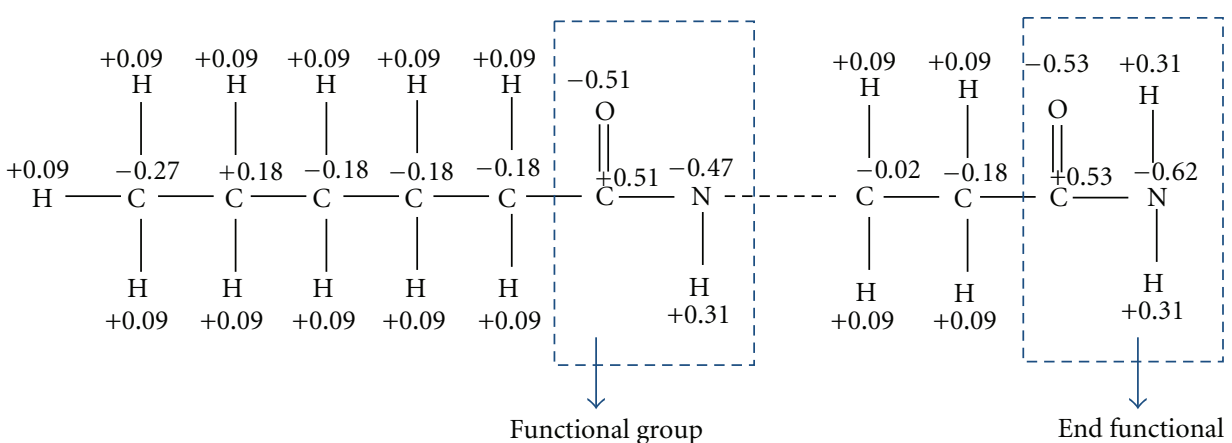

(c)

Figure 2: Distribution of partial charges (a) 12-aminolauric acid, (b) PBT, (c) Nylon6.

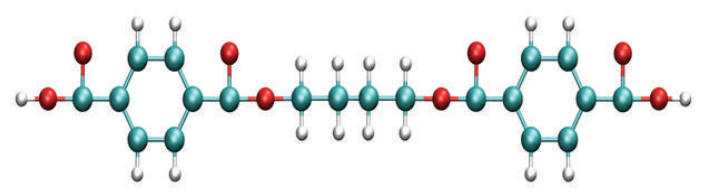

Figure 3: Single chain molecular model of PBT.

3.1.2. FTIR Results of PBT, OMMT, and PCN. In our previous work, we have observed that the organic modifier, 12-aminolauric acid, is intercalated between clay sheets with hydrogen bonds and ionic interactions generated by end functional groups of organic modifier with surface oxygen of interlayer clay sheets. Nanocomposites are prepared by intercalation of polymer and MMT with the aid of organic modifier [26]. The spectroscopic analysis on nylon6-PCN system has been reported and revealed the hydrogen formation between intercalated polymer and organic modifier and surface oxygen of clay sheet lying in the interlayer clay gallery in the polymer clay nanocomposite [26]. In the present work, the same OMMT is used in conjunction with PBT and the 


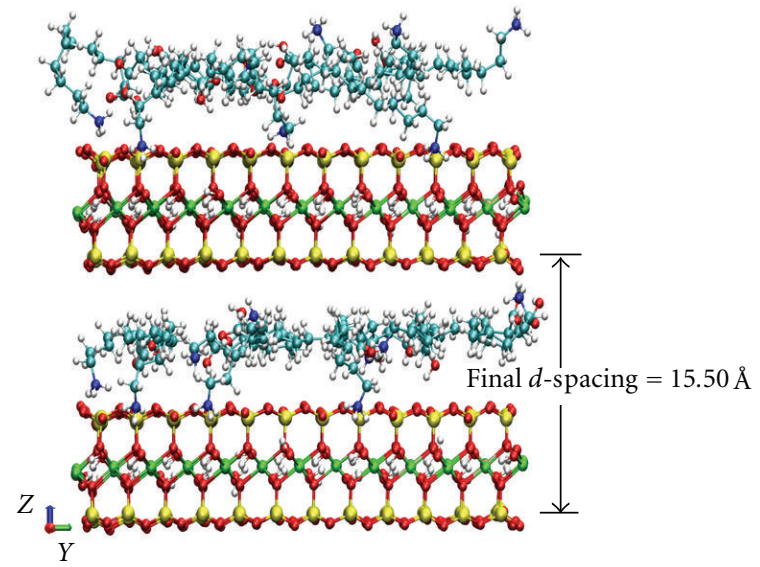

FIGURE 4: Final OMMT model.

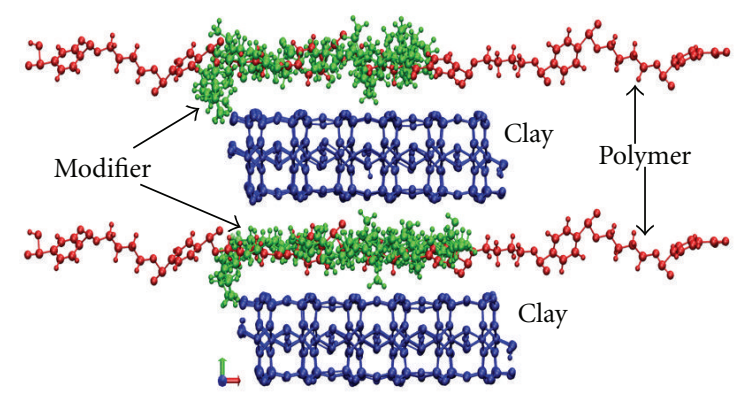

Figure 5: Initial PBT-PCN model.

TABLE 1: Estimated mass percentage of PBT with respect to clay.

\begin{tabular}{lc}
\hline Model & Intercalated polymer wt\% with clay \\
\hline PCN $(1)$ & 1.96 \\
$\operatorname{PCN}(2)$ & 4.19 \\
$\operatorname{PCN}(3)$ & 6.41 \\
$\operatorname{PCN}(4)$ & 8.64 \\
$\operatorname{PCN}(5)$ & 10.87 \\
$\operatorname{PCN}(6)$ & 13.10 \\
\hline
\end{tabular}

TABle 2: Experimental $d$-spacing.

\begin{tabular}{lc}
\hline Sample & $d$-spacing range/ $\AA$ \\
\hline Pure MMT & $11.56-12.25$ \\
OMMT & $15.60-17.43$ \\
PBT-PCN & $13.90-14.53$ \\
Nylon6-PCN & 13.50 \\
\hline
\end{tabular}

spectroscopic results of PBT, OMMT, and PBT-PCN are discussed here. The PA FTIR spectra of OMMT, PBT, and PCN are shown in Figure 9 and the corresponding band assignments are shown in Table 3. As indicated in Figure 9 and Table 3 , the band contribution in PCN from PBT is much more prominent than that from OMMT due to low

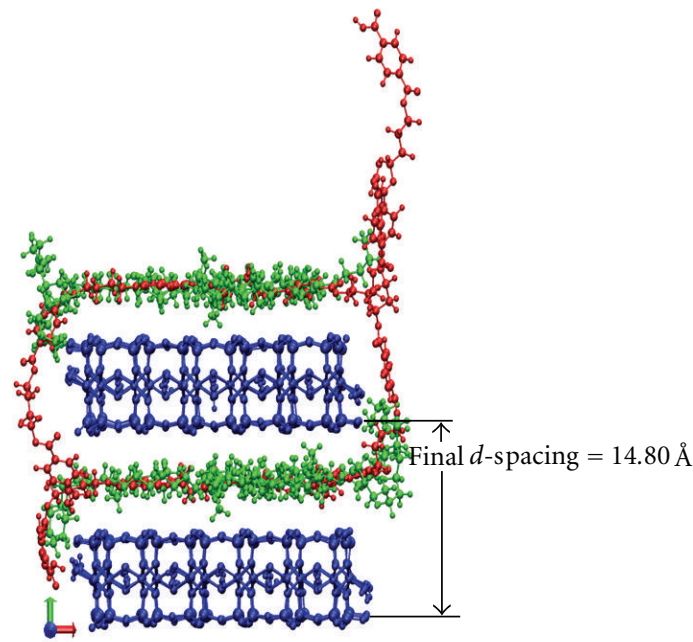

FIgURE 6: Final PBT-PCN model.

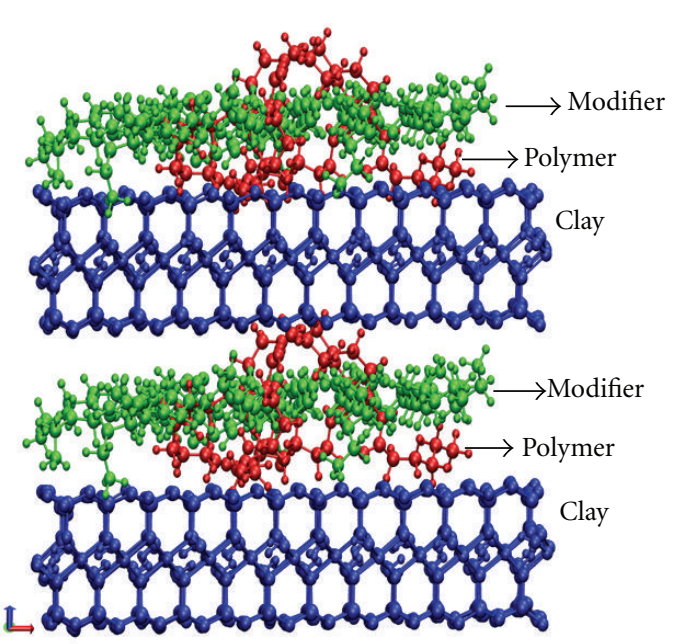

FIgURE 7: Initial Nylon6-PCN model.

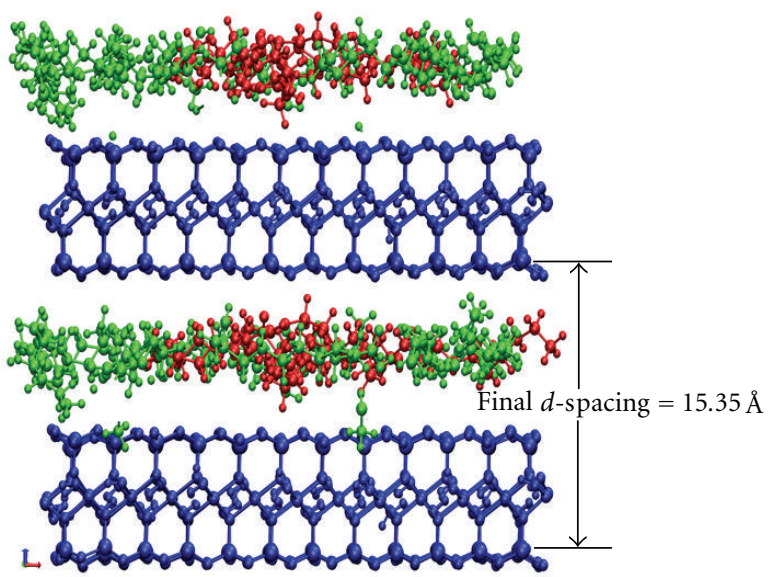

Figure 8: Final Nylon6-PCN model. 


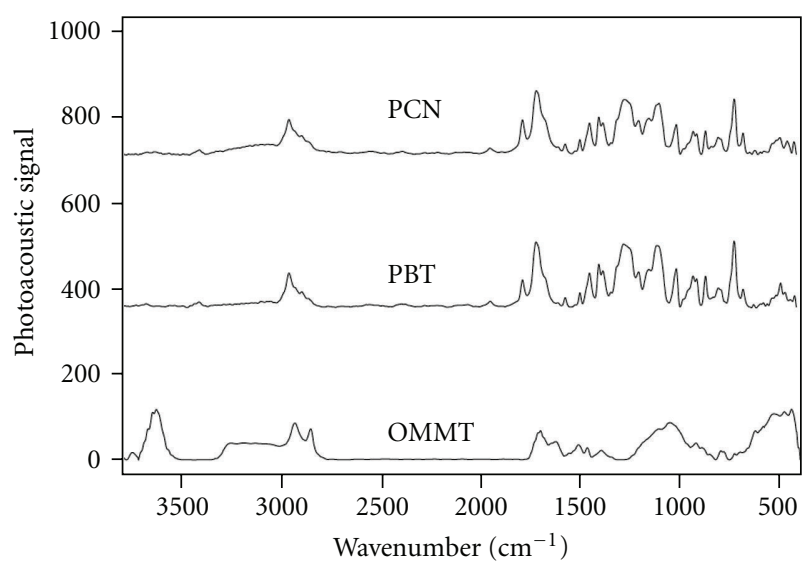

FIgURE 9: Photo acoustic FTIR spectra of OMMT, PBT, and PCN in the energy range of $4000-400 \mathrm{~cm}^{-1}$ at scan speed of $0.15 \mathrm{~cm}^{-1}$.

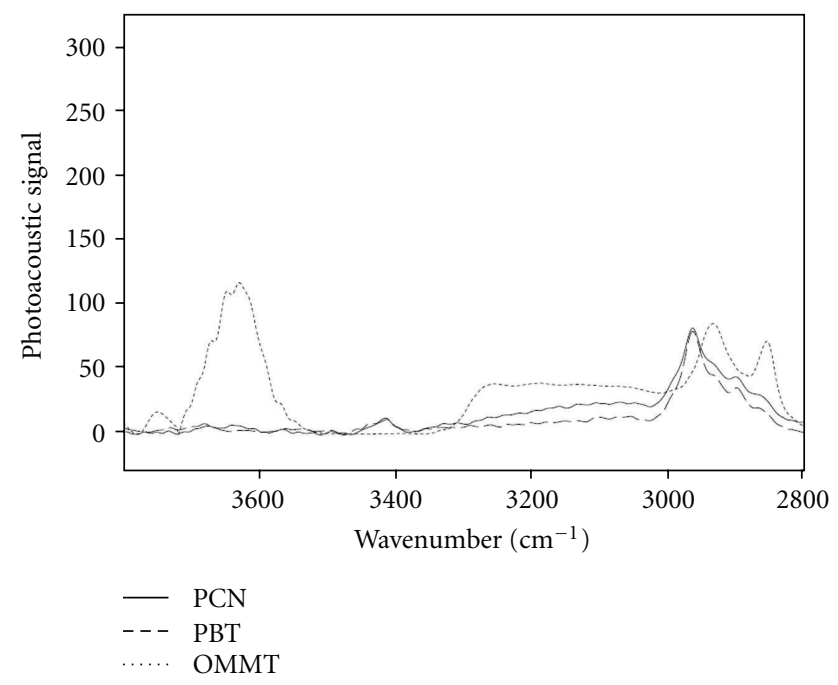

FIgUre 10: Photo acoustic FTIR spectra of OMMT, PBT, and PCN in the energy range of $3800-2800 \mathrm{~cm}^{-1}$ at scan speed of $0.15 \mathrm{~cm}^{-1}$.

weight fraction of OMMT in PCN as well as the strong bands from PBT. FTIR spectra of PCN, PBT, and OMMT are shown in Figure 10 in the range of $3800-2800 \mathrm{~cm}^{-1}$. It is observed that the sharp $\mathrm{O}-\mathrm{H}$ stretching band at 3645$3628 \mathrm{~cm}^{-1}$ has affected the spectrum of PCN and created a broad band in the range of $3633-3679 \mathrm{~cm}^{-1}$ and the broad band of ionically bonded $\mathrm{N}-\mathrm{H}$ stretching at $3256-3035 \mathrm{~cm}^{-1}$ generating a bulge at $3260-3047 \mathrm{~cm}^{-1}$ in PCN associated with aromatic $\mathrm{C}-\mathrm{H}$ stretching from PBT. FTIR spectra of PCN, PBT, and OMMT are shown in Figure 11 in between 2000 and $1000 \mathrm{~cm}^{-1}$. In this energy-region, bands from PBT are very strong and thus the bands in both PBT and PCN are almost identical. Most bands from OMMT are overlapped by $\mathrm{PBT}$, and $\mathrm{Si}-\mathrm{O}$ stretching band is not visible in PCN. The PA FTIR spectra of PCN, PBT, and OMMT in the range of $1000-400 \mathrm{~cm}^{-1}$ are shown in Figure 12. The inplane ring deformation vibration of PBT at $633 \mathrm{~cm}^{-1}$ has shifted to the lower energy side by $9 \mathrm{~cm}^{-1}$ in the PCN. The tripled $\mathrm{Al}-\mathrm{O}, \mathrm{Si}-\mathrm{O}$ vibration and in-plane ring deformation vibration shows broader band than that of pure PBT. From Figure 12, it can be seen that the sharp out-of-plane ring deformation vibration of PBT at $497 \mathrm{~cm}^{-1}$ is suppressed and the out-of-plane ring deformation vibration of PBT at $476 \mathrm{~cm}^{-1}$ is absent in PCN. These phenomena indicate that ring deformations in $\mathrm{PBT}$ are restricted by OMMT due to intercalation. It is evident that $\mathrm{Si}-\mathrm{O}-\mathrm{Si}$ deformation from OMMT appears in PCN at $463 \mathrm{~cm}^{-1}$ and shifted to the lower energy side by $15 \mathrm{~cm}^{-1}$ and this shift in PCN is probably due to the formation of bonding of PBT with silica tetrahedral oxygen through the hydrogen bond between the functional groups of PBT and 12-aminolauric acid. Due to this effect the $\mathrm{Si}-\mathrm{O}$ stretching band in PCN disappears. Wang et al. [36] found that during melt processing when $\mathrm{PBT} / \mathrm{PET}$ blends are filled with silica nanoparticles, hydroxyl end groups of PET and PBT react with the surface hydroxyl groups of $\mathrm{SiO}_{2}$ which is shown by X-ray photoelectron Spectroscopy (XPS) tests. Fermeglia et al. [48] investigated the binding energy between poly(Butylene terephtalateco-thiodiethylene terephtalate), clay and different organic modifiers using molecular simulations and have found that $\mathrm{NH}_{2},-\mathrm{COOH}$, or $-\mathrm{SH}$ groups in organic modifiers generally lead to a good interaction between modifiers and polymers.

3.1.3. Crystallinity of PBT and PCN. DSC tests are conducted on the pure PBT and PCN and results are shown in Table 4; it is observed that the pure PBT shows $0.5 \%$ higher crystallinity than that of PCN. This observation of reduced crystallinity of PCN with respect to a polymer has been observed earlier in Nylon6-PCN [10]. As shown in Table 4, Nylon6-PCN with $9 \%$ of clay loading shows $4.56 \%$ reduction in crystallinity.

3.1.4. Nanomechanical Properties of PBT and PCN. In the present work, nanoindentation tests for PBT and PBT-PCN are performed in load control mode. Figure 13 is the representative L-D curves for PBT and PBT-PCN films. Maximum load was maintained for period of $5 \mathrm{~s}$ between loading and unloading sequence in order to reduce the time-dependent deformation. The elastic modulus and hardness values for PBT and PBT-PCN are presented in Table 5. Nylon6 and Nylon6-PCN nanomechanical tests were performed in load control mode [10] and the results are presented in Table 5.

\subsection{Interactions in PCNs System}

3.2.1. Nonbonded Interactions between Organic Modifier and Clay. Interaction energies between different constituents of OMMT and PCNs are calculated using NAMDEnergy module of NAMD software. Nonbonded interactions, van der waals and electrostatic, are calculated in terms of attractive and repulsive interactions. Among different initial $d$-spacing of OMMT, $d$-spacing of $17.60 \AA$ OMMT model predicts final $d$-spacing of $15.50 \AA$ which is very close to experimental $d$-spacing of $15.60 \AA$. Based on this comparison of $d$-spacing, the OMMT model is chosen for simulation. Among six different PCNs models, the PCN model which contains $6.41 \mathrm{wt} \%$ of PBT predicts the simulated $d$-spacing of $14.80 \AA$ which is close to experimental $d$-spacing of $14.53 \AA$. 
TABLE 3: Band assignments of photoacoustic FTIR spectra of OMMT, PBT, and PCN.

\begin{tabular}{|c|c|c|c|}
\hline Sample & Wave number range $\left(\mathrm{cm}^{-1}\right)$ & Bands & Reference \\
\hline \multirow{22}{*}{ OMMT } & $3646-3628$ & $\mathrm{O}-\mathrm{H}$ stretching of structural hydroxyl group & {$[26]$} \\
\hline & $3256-3035$ & Ionic bonded $\mathrm{N}-\mathrm{H}$ stretching & \\
\hline & 2932 & $\mathrm{C}-\mathrm{H}$ asymmetric stretching & \\
\hline & 2853 & C-H symmetric stretching & \\
\hline & $1713-1701$ & $\mathrm{C}=\mathrm{O}$ stretching & \\
\hline & 1623 & Combination of $\mathrm{O}-\mathrm{H}$ deformation and $\mathrm{N}-\mathrm{H}$ bending & \\
\hline & 1511 & Asymmetric $\mathrm{R}-\mathrm{COO}^{-}$stretching & \\
\hline & 1466 & $\mathrm{CO}-\mathrm{H}$ bending & \\
\hline & 1396 & Symmetric R-COO${ }^{-}$stretching & \\
\hline & 1112 & Si-O in-plane stretching & \\
\hline & 1060 & Si-O out-of-plane stretching & \\
\hline & 1022,997 & $\mathrm{Si}-\mathrm{O}$ in-plane stretching & \\
\hline & 963 & $\mathrm{Si}-\mathrm{OH}$ vibrations & \\
\hline & 921 & $\mathrm{Al}-\mathrm{O} / \mathrm{Al}-\mathrm{OH}$ stretching vibration & \\
\hline & 884 & $\mathrm{Al}-\mathrm{FeOH}$ deformation & \\
\hline & 847 & $\mathrm{Al}-\mathrm{MgOH}$ deformation & \\
\hline & 799 & Si-O stretching of quartz and silica & \\
\hline & 727 & $\mathrm{Si}-\mathrm{O}$ deformation perpendicular to optical axis & \\
\hline & 699 & $\mathrm{Si}-\mathrm{O}$ deformation parallel to optical axis & \\
\hline & 623 & Coupled Al-O and Si-O out-of-plane vibration & \\
\hline & 531 & Al-OSi deformation & \\
\hline & 478 & Si-OSi vibration & \\
\hline \multirow{21}{*}{ PBT } & 3417 & -OH stretching & \\
\hline & 3052 & Aromatic C-H stretching & {$[35]$} \\
\hline & 2962 & $\mathrm{C}-\mathrm{H}_{2}$ stretching & {$[36]$} \\
\hline & 2895 & Aliphatic C-H asymmetric stretching & {$[35]$} \\
\hline & 2863 & Aliphatic C-H symmetric stretching & {$[35]$} \\
\hline & 1722 & $\mathrm{C}=\mathrm{O}$ stretching & {$[37]$} \\
\hline & 1583 & Aromatic $\mathrm{C}=\mathrm{C}$ stretching & {$[38]$} \\
\hline & 1504 & Aliphatic $\mathrm{C}-\mathrm{H}_{2}$ bending & {$[37]$} \\
\hline & 1453 & Aliphatic $\mathrm{C}-\mathrm{H}_{2}$ bending & {$[39]$} \\
\hline & 1407 & Aliphatic aromatic $\mathrm{C}-\mathrm{H}$ in-of-plane bending & {$[36]$} \\
\hline & 1387 & $\mathrm{CH}_{2}$ wagging & {$[39]$} \\
\hline & 1281 & $(\mathrm{C}=\mathrm{O}-)-\mathrm{O}$ stretching & {$[35]$} \\
\hline & 1110 & $\mathrm{CH}_{2}-\mathrm{O}$ stretching & {$[35]$} \\
\hline & 1017 & Aromatic $\mathrm{C}-\mathrm{H}$ bending & {$[35]$} \\
\hline & 873 & Aromatic C-H bending & {$[40]$} \\
\hline & 808 & Aromatic $\mathrm{C}-\mathrm{H}$ bending & {$[37]$} \\
\hline & 729 & Aromatic C-H out-of-plane bending & {$[35,36]$} \\
\hline & 685 & Aromatic $=\mathrm{C}-\mathrm{H}$ out - of-plane deformation & {$[38]$} \\
\hline & 633 & Aromatic in-plane deformation & {$[38]$} \\
\hline & 497 & Aromatic out-of-plane deformation & {$[38]$} \\
\hline & 476 & Aromatic out-of-plane deformation & {$[38]$} \\
\hline
\end{tabular}


Table 3: Continued.

\begin{tabular}{|c|c|c|c|}
\hline Sample & Wave number range $\left(\mathrm{cm}^{-1}\right)$ & Bands & Reference \\
\hline & $3633-3679$ & O-H stretching of structural hydroxyl group-OMMT & {$[26]$} \\
\hline & 3413 & $-\mathrm{OH}$ stretching & \\
\hline & $3260-3047$ & Coupled $\mathrm{N}-\mathrm{H}$ stretching and aromatic $\mathrm{C}-\mathrm{H}$ stretching & {$[35]$} \\
\hline & 2963 & $\mathrm{C}-\mathrm{H}_{2}$ stretching & {$[36]$} \\
\hline & 2895 & Aliphatic $\mathrm{C}-\mathrm{H}$ asymmetric stretching & {$[35]$} \\
\hline & 2858 & Aliphatic $\mathrm{C}-\mathrm{H}$ symmetric stretching & {$[35]$} \\
\hline & 1719 & $\mathrm{C}=\mathrm{O}$ stretching & {$[37]$} \\
\hline & 1576 & Aromatic $\mathrm{C}=\mathrm{C}$ stretching & {$[38]$} \\
\hline & 1503 & Aliphatic $\mathrm{C}-\mathrm{H}_{2}$ bending & {$[37]$} \\
\hline & 1452 & Aliphatic $\mathrm{C}-\mathrm{H}_{2}$ bending & {$[39]$} \\
\hline & 1406 & Aromatic $\mathrm{C}-\mathrm{H}$ in-of-plane bending & {$[36]$} \\
\hline \multirow[t]{12}{*}{ PCN } & 1387 & $\mathrm{CH}_{2}$ wagging & {$[39]$} \\
\hline & 1278 & $(\mathrm{C}=\mathrm{O}-)-\mathrm{O}$ stretching & {$[35]$} \\
\hline & 1105 & $\mathrm{CH}_{2}-\mathrm{O}$ stretching & {$[35]$} \\
\hline & 1020 & Aromatic $\mathrm{C}-\mathrm{H}$ bending & {$[35]$} \\
\hline & 873 & Aromatic $\mathrm{C}-\mathrm{H}$ bending & {$[40]$} \\
\hline & 810 & Aromatic $\mathrm{C}-\mathrm{H}$ bending & {$[37]$} \\
\hline & 729 & Aromatic $\mathrm{C}-\mathrm{H}$ out-of-plane bending & {$[35,36]$} \\
\hline & 685 & Aromatic $=\mathrm{C}-\mathrm{H}$ out-of-plane deformation & {$[38]$} \\
\hline & 652 & Aromatic in-plane deformation & {$[38]$} \\
\hline & 624 & Tripled Al-O, Si-O out-of-plane and aromatic in-plane deformation & {$[26]$} \\
\hline & 497 & Aromatic out-of-plane deformation & {$[38]$} \\
\hline & 463 & Si-OSi deformation & {$[26]$} \\
\hline
\end{tabular}

TABLE 4: DSC results of PBT, Nylon6, and PCNs.

\begin{tabular}{lcc}
\hline Materials & Enthalpy $(\mathrm{J} / \mathrm{g})$ & Crystallinity $(\%)$ \\
\hline PBT & 50.21 & 35.6 \\
PBT-PCN & 49.56 & 35.1 \\
Nylon6 & 56.06 & 27.61 \\
Nylon6-PCN & 46.81 & 23.05 \\
\hline
\end{tabular}

TABle 5: Nanomechanical properties of PCNs.

\begin{tabular}{lcccc}
\hline Parameters & PBT & PBT-PCN & Nylon6 & Nylon6-PCN \\
\hline Crystallinity (\%) & 35.6 & 35.1 & 27.6 & 23.1 \\
Elastic modulus (GPa) & 1.40 & 2.20 & 3.35 & 5.46 \\
Hardness (GPa) & 0.09 & 0.14 & 0.12 & 0.17 \\
\hline
\end{tabular}

TABLE 6: Nonbonded interaction energies of OMMT constituents.

\begin{tabular}{lc}
\hline OMMT constituents & Nonbonded energy $(\mathrm{kcal} / \mathrm{mol})$ \\
\hline Clay-modifier backbone & -894 \\
Clay-modifier functional group & -1176 \\
\hline
\end{tabular}

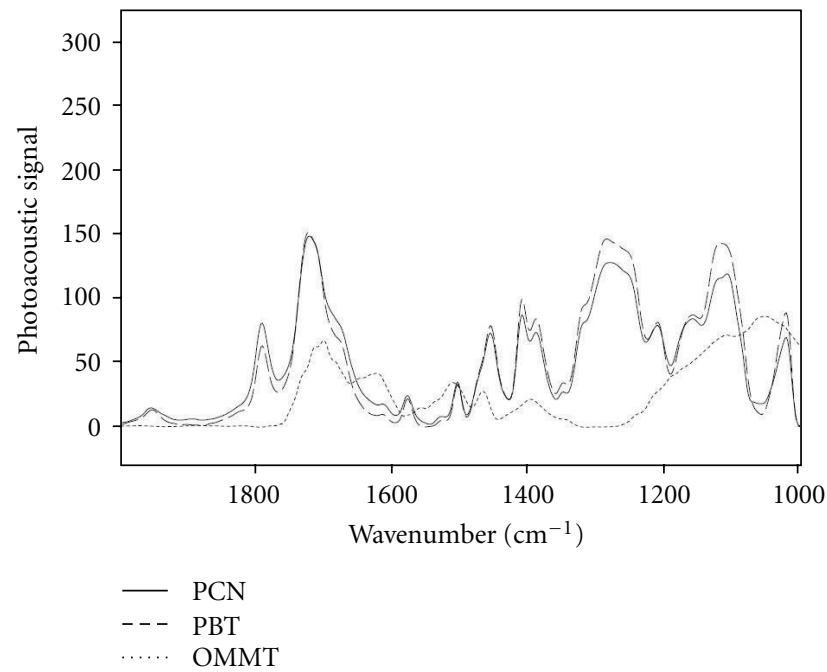

FIgUre 11: Photo acoustic FTIR spectra of OMMT, PBT, and PCN in the energy range of $2000-1000 \mathrm{~cm}^{-1}$ at scan speed of $0.15 \mathrm{~cm}^{-1}$.

The same OMMT model with Nylon6 is simulated and it predicts $d$-spacing of $15.35 \AA$. Non-bonded interactions between organic modifier and clay are calculated and the interaction energies are shown in Table 6 . Positive values 
TABLE 7: Nonbonded energies of individual atoms of organic modifier with clay.

\begin{tabular}{lccc}
\hline Component of modifier and clay & $\begin{array}{c}\text { Electrostatic energy }(\mathrm{kcal} / \mathrm{mol}) \\
{[\text { Col-A }]}\end{array}$ & $\begin{array}{c}\text { Van der waals energy } \\
(\mathrm{kcal} / \mathrm{mol})[\text { Col-B }]\end{array}$ & $\begin{array}{c}\text { Total nonbonded energy }(\mathrm{kcal} / \mathrm{mol}) \\
{[\mathrm{Col}-\mathrm{A}+\mathrm{Col}-\mathrm{B}]}\end{array}$ \\
\hline Clay-modifier backbone hydrogen & -2503 & -87 & -2590 \\
Clay-modifier backbone carbon & +1954 & -257 & +1697 \\
Clay-modifier functional hydrogen & -2392 & -8 & -2400 \\
Clay-modifier functional nitrogen & +497 & -0.5 & -48 \\
Clay-modifier functional oxygen & +1689 & -25 & +497 \\
Clay-modifier functional carbon & -890 & & -915 \\
\hline
\end{tabular}

TABLE 8: Nonbonded energies PCNs.

\begin{tabular}{|c|c|c|c|}
\hline $\begin{array}{l}\text { Component of } \\
\text { PCN }\end{array}$ & $\begin{array}{c}\text { Electrostatic } \\
\text { energy } \\
(\mathrm{kcal} / \mathrm{mol}) \\
{[\mathrm{Col}-\mathrm{A}]}\end{array}$ & $\begin{array}{c}\text { Van der waals } \\
\text { energy } \\
(\mathrm{kcal} / \mathrm{mol}) \\
{[\text { Col-B }]}\end{array}$ & $\begin{array}{c}\text { Total } \\
\text { nonbonded } \\
\text { energy } \\
(\mathrm{kcal} / \mathrm{mol}) \\
{[\mathrm{Col}-\mathrm{A}+\mathrm{Col}-\mathrm{B}]}\end{array}$ \\
\hline \multicolumn{4}{|c|}{ PBT-PCN } \\
\hline Clay-polymer & -36 & -165 & -201 \\
\hline Clay-modifier & -1836 & -316 & -2152 \\
\hline Polymer-modifier & -93 & -43 & -136 \\
\hline \multicolumn{4}{|c|}{ Nylon6-PCN } \\
\hline Clay-polymer & 12 & -182 & -170 \\
\hline Clay-modifier & -1464 & -375 & -1839 \\
\hline Polymer-modifier & -209 & -30 & -239 \\
\hline
\end{tabular}

indicate repulsive interactions and negative values indicate attractive interactions between constituents and higher magnitude denotes greater interactions. Interaction energy values of organic modifiers are the sum of backbone and functional group interaction energies. Among these two components, functional group of organic modifier shows higher interaction with clay than the backbone of the organic modifier. This is because of higher positive net charge in the functional group compared to the backbone. Functional group interactions are composed of $-1096 \mathrm{kcal} / \mathrm{mol}$ in electrostatic interaction energy and $-80 \mathrm{kcal} / \mathrm{mol}$ in van der waals interaction energy and backbone interactions are composed of $-549 \mathrm{kcal} / \mathrm{mol}$ electrostatic interaction energy and $-345 \mathrm{kcal} / \mathrm{mol}$ van der waals interaction energy. It is observed that the electrostatic interactions are the major components of both modifier functional group and modifier backbone interaction energies with the clay. More detailed quantitative results are presented in Table 7 . Here, it is observed that the major component of attractive interaction with clay is from the hydrogen atoms of modifier. Even though the partial charge of the backbone hydrogen smaller is compared to functional group hydrogen as shown in Figure 2(a), backbone hydrogen shows higher interaction because of its presence in significant numbers.

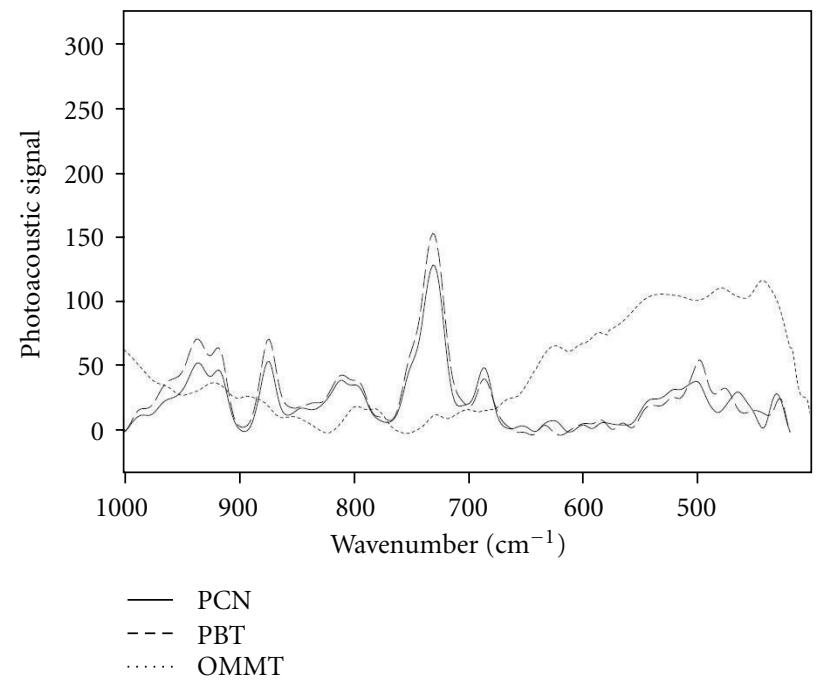

Figure 12: Photo acoustic FTIR spectra of OMMT, PBT, and PCN in the energy range of $1000-400 \mathrm{~cm}^{-1}$ at scan speed of $0.15 \mathrm{~cm}^{-1}$.

3.2.2. Nonbonded Interactions of PBT-PCN and Nylon6$P C N$ System. The nonbonded interaction energies between constituents of PBT-PCN and Nylon6-PCN are presented in Table 8 . Interaction energy between the clay and modifier is attractive and higher than interaction energy between clay and polymer. This is because of higher partial charges of individual atoms in modifiers than the polymers. Interaction energies between clay and polymer are attractive and higher than the interaction energy between polymer and modifier. Detailed results are shown in Table 9 and it is observed that the interaction energy between clay and modifier functional group is attractive and higher than among other constituents in both PCNs. This higher interaction between clay and modifier functional groups could be attributed to higher positive partial charges in functional groups atoms as shown in Figure 2(a). Similarly, modifier backbone also has higher attractive interactions with clay compared to the polymer functional group and backbone in both PCNs.

Polymer functional group has negative partial charges as shown in Figure 2(b) thus it induces repulsive interaction with clay in both PCNs systems. Interaction energies between clay and individual atoms of organic modifier are shown in Table 10. It is observed that the organic modifier hydrogen 
TABLE 9: Nonbonded energies of modifier and polymer with clay.

Component of modifier, polymer, and clay in PCN
Electrostatic energy ( $\mathrm{kcal} / \mathrm{mol}) \quad$ Van der waals energy $(\mathrm{kcal} / \mathrm{mol})$

Total nonbonded energy $(\mathrm{kcal} / \mathrm{mol})$

$$
\text { [Col-A] }
$$

$[$ Col-A + Col-B $]$

\begin{tabular}{lccc}
\hline & & PBT-PCN & -864 \\
\hline Clay-modifier backbone & -582 & -282 & -1289 \\
Clay-modifier functional group & -1255 & -34 & -358 \\
Clay-polymer backbone & -250 & -108 & +157 \\
Clay-polymer functional group & +213 & -56 & -782 \\
\hline Clay-modifier backbone & & Nylon6-PCN & -297 \\
Clay-modifier functional group & -485 & -77 & -1056 \\
Clay-polymer backbone & -979 & -123 & -306 \\
Clay-polymer functional group & -183 & -62 & +93 \\
\hline
\end{tabular}

TABLE 10: Nonbonded energies between individual atoms of organic modifier and clay.

\begin{tabular}{|c|c|c|c|}
\hline $\begin{array}{l}\text { Individual atoms of organic modifiers } \\
\text { and clay }\end{array}$ & $\begin{array}{l}\text { Electrostatic energy }(\mathrm{kcal} / \mathrm{mol}) \\
{[\text { Col-A }]}\end{array}$ & $\begin{array}{l}\text { Van der waals energy }(\mathrm{kcal} / \mathrm{mol}) \\
{[\text { Col-B }]}\end{array}$ & $\begin{array}{c}\text { Total nonbonded energy } \\
(\mathrm{kcal} / \mathrm{mol}) \\
{[\mathrm{Col}-\mathrm{A}+\mathrm{Col}-\mathrm{B}]}\end{array}$ \\
\hline \multicolumn{4}{|c|}{ PBT-PCN } \\
\hline Clay-modifier backbone hydrogen & -2512 & -67 & -2579 \\
\hline Clay-modifier backbone carbon & +1930 & -215 & +1715 \\
\hline Clay-modifier functional hydrogen & -2564 & -7 & -2571 \\
\hline Clay-modifier functional nitrogen & +546 & +37 & +583 \\
\hline Clay-modifier functional oxygen & +1628 & -42 & +1586 \\
\hline Clay-modifier functional carbon & -865 & -22 & -887 \\
\hline \multicolumn{4}{|c|}{ Nylon6-PCN } \\
\hline Clay-modifier backbone hydrogen & -2085 & -72 & -2157 \\
\hline Clay-modifier backbone carbon & +1600 & -226 & +1374 \\
\hline Clay-modifier functional hydrogen & -2071 & -7 & -2078 \\
\hline Clay-modifier functional nitrogen & +444 & -2 & +442 \\
\hline Clay-modifier functional oxygen & +1359 & -44 & +1315 \\
\hline Clay-modifier functional carbon & -711 & -24 & -735 \\
\hline
\end{tabular}

atoms show higher magnitude of attractive interactions with clay as observed in the OMMT system. Interaction energies of individual polymer atoms with clay are shown in Table 11. Here, hydrogen and carbon atoms show attractive interaction with clay while the other atoms show repulsive interactions. Functional group carbon atoms contribute towards more attractive interactions and greater negative partial charge of oxygen atoms contribute to more repulsive interactions. As shown in Table 12, polymer backbone has higher repulsive interaction with modifier functional group and lesser repulsive interaction with modifier backbone. Polymer functional group has higher attractive interaction with modifier functional group and lesser attractive interaction with backbone. Similar nature of interactions have been reported in our previous work [11].

3.2.3. Summary of Interaction of OMMT, PBT-PCN, and Nylon6-PCN System. As mentioned in Section 1, nonbonded interactions play a major role in PCNs and they affect the crystallinity and mechanical properties of PCNs. Based on our results, more than $80 \%, 75 \%, 70 \%$ of interaction energies are a result of electrostatic interaction for OMMT, PBT-PCN and Nylon6-PCN respectively. Figures 14 and 15 show overall interaction energy map for PBT-PCN, and Nylon6-PCN, respectively. The two energy maps have similar pattern in terms of attractive and repulsive interactions 
TABLE 11: Nonbonded energies between individual atoms of polymer and clay.

\begin{tabular}{|c|c|c|c|}
\hline Component of polymer and clay in PCN & $\begin{array}{l}\text { Electrostatic energy } \\
(\mathrm{kcal} / \mathrm{mol})[\mathrm{Col}-\mathrm{A}]\end{array}$ & $\begin{array}{l}\text { Van der waals energy } \\
(\mathrm{kcal} / \mathrm{mol})[\mathrm{Col}-\mathrm{B}]\end{array}$ & $\begin{array}{c}\text { Total nonbonded energy } \\
(\mathrm{kcal} / \mathrm{mol})[\mathrm{Col}-\mathrm{A}+\mathrm{Col}-\mathrm{B}]\end{array}$ \\
\hline \multicolumn{4}{|c|}{ PBT-PCN } \\
\hline Clay-polymer aromatic hydrogen & -301 & -10 & -311 \\
\hline Clay-polymer backbone hydrogen & -380 & -10 & -390 \\
\hline Clay-polymer aromatic carbon & +188 & -59 & +129 \\
\hline Clay-polymer backbone carbon & +243 & -29 & +214 \\
\hline Clay-polymer functional hydrogen & -90 & -0.2 & -90.2 \\
\hline Clay-polymer functional oxygen & +1127 & -36 & 1091 \\
\hline Clay-polymer functional carbon & -824 & -20 & -844 \\
\hline \multicolumn{4}{|c|}{ Nylon6-PCN } \\
\hline Clay-polymer backbone hydrogen & -1056 & -19 & -1075 \\
\hline Clay-polymer backbone carbon & +872 & -104 & +768 \\
\hline Clay-polymer functional nitrogen & +593 & -27 & +566 \\
\hline Clay-polymer functional hydrogen & -424 & -2 & -426 \\
\hline Clay-polymer functional oxygen & +589 & -13 & +576 \\
\hline Clay-polymer functional carbon & -600 & -20 & -620 \\
\hline Clay-polymer backbone hydrogen & -1056 & -19 & -1075 \\
\hline
\end{tabular}

TABLE 12: Nonbonded energies between polymer and organic modifier.

\begin{tabular}{|c|c|c|c|}
\hline Component of modifier and polymer in $\mathrm{PCN}$ & $\begin{array}{l}\text { Electrostatic energy } \\
(\mathrm{kcal} / \mathrm{mol})[\mathrm{Col}-\mathrm{A}]\end{array}$ & $\begin{array}{l}\text { Van der waals energy } \\
(\mathrm{kcal} / \mathrm{mol})[\mathrm{Col}-\mathrm{B}]\end{array}$ & $\begin{array}{c}\text { Total nonbonded energy } \\
(\mathrm{kcal} / \mathrm{mol})[\mathrm{Col}-\mathrm{A}+\mathrm{Col}-\mathrm{B}]\end{array}$ \\
\hline \multicolumn{4}{|c|}{ PBT-PCN } \\
\hline Polymer backbone-modifier backbone & +115 & -29 & +86 \\
\hline Polymer backbone-modifier functional & +209 & -10 & +199 \\
\hline Polymer functional—modifier backbone & -132 & -12 & -144 \\
\hline Polymer functional-modifier functional & -285 & +7 & -278 \\
\hline \multicolumn{4}{|c|}{ Nylon6-PCN } \\
\hline Polymer backbone-modifier backbone & +58 & -20 & +38 \\
\hline Polymer backbone-modifier functional & +91 & -11 & +80 \\
\hline Polymer functional—modifier backbone & -94 & -11 & -105 \\
\hline Polymer functional—modifier functional & -264 & +11 & -253 \\
\hline
\end{tabular}

between different constituents of PCNs. These energy maps indicate that the PBT-PCN system has greater magnitude of interaction energies between different constituents than the Nylon6-PCN system. In all three systems, OMMT, PBTPCN, and Nylon6-PCN, modifier shows attractive interactions with the clay. Further, in PBT-PCN system, modifiers have $17 \%$ higher attractive interactions with clay than in Nylon6-PCN system. Polymer has attractive interaction with clay and modifier in both systems. In terms of interaction energy magnitudes, almost equal interaction of polymer with clay is observed in both systems and $75 \%$ higher interaction with organic modifier is observed in Nylon6-PCN compared to PBT-PCN.
3.3. Discussion. Our previous work has shown that the molecular interactions between clay, modifier, and polymer results in significant alteration of polymer to a very large extent in PCN [10]. This is the basis of the altered phase theory to explain the significant improvement in mechanical properties of PCN as a result of addition of small amounts of well-dispersed clay nanoparticles in the polymer. The attractive interactions between functional groups of the polymer with the modifier and concurrent repulsive interaction between modifier and polymer backbone result in reduction of crystallinity of the surrounding polymer.

In the current work with PBT-PCN system we have observed reduction in crystallinity and improved mechanical 


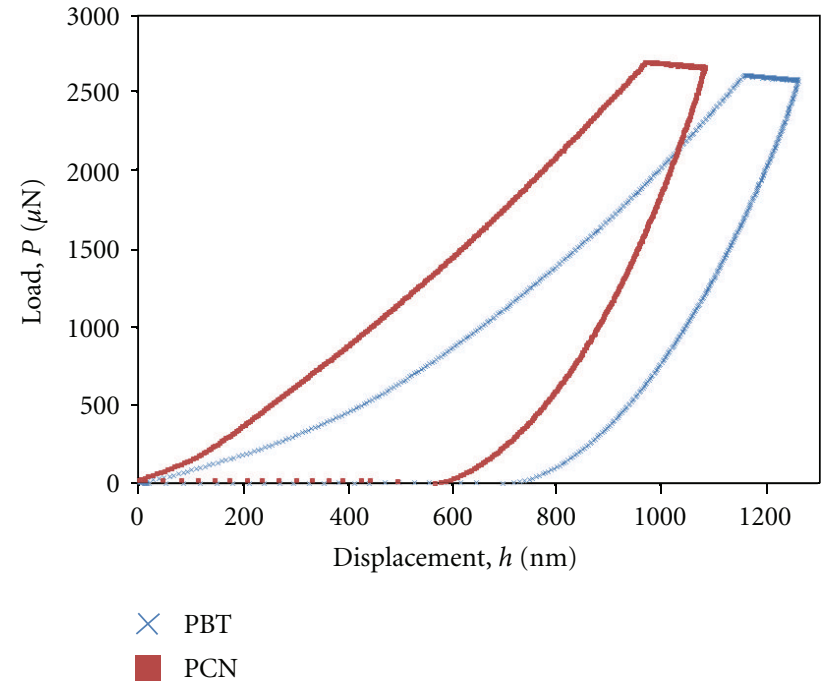

FIGURE 13: Representative load displacement (L-D) curves for PBT and PCN.

properties of the PCN with respect to the pristine polymer. We have seen similar phenomena of reduction in crystallinity and improved mechanical properties of Nylon6-PCN [10]; however, the magnitudes of reduction in crystallinity for the two PCNs are different and the improvement in mechanical properties is different. Based on the interaction energy maps for the two systems shown in Figures 14 and 15, the mechanism of attractive interaction between functional group of the polymer and modifier and repulsive interaction between backbone of the polymer and the modifier leading to changes in polymer crystallinity is present, although the magnitudes of the interaction energies are different. In the case of Nylon6-PCN the reduction in crystallinity is 16.5 $\%$ while the reduction in crystallinity is $0.5 \%$ in PBT$\mathrm{PCN}$. The improvement in elastic modulus and hardness values for Nylon6-PCN is $63 \%$ and $42 \%$, respectively, with respect to pristine Nylon6 while the improvement in elastic modulus and hardness values for PBT-PCN is only $10 \%$ and $23 \%$, respectively, with respect to pristine PBT. It appears that in the case of Nylon6-PCN, the clay-modifier system has significantly altered crystallinity and improved the mechanical properties, while the same clay-modifier system has impacted only moderately the crystallinity and mechanical properties of the PBT-PCN system.

The comparison of interaction energy maps for the two PCNs shown in Figures 14 and 15 reveals that the interaction energies between polymer and modifier and polymer and clay are higher in the PBT-PCN system than the Nylon6-PCN system. The attractive interaction energy and repulsive interaction energy between polymer and modifier are $422 \mathrm{kcal} / \mathrm{mol}$ and $285 \mathrm{kcal} / \mathrm{mol}$ for PBT-PCN while the attractive and repulsive interaction energies for Nylon6PCN are $358 \mathrm{kcal} / \mathrm{mol}$ and $118 \mathrm{kcal} / \mathrm{mol}$, respectively. The attractive and repulsive interaction energies between clay and polymer are $157 \mathrm{kcal} / \mathrm{mol}$ and $358 \mathrm{kcal} / \mathrm{mol}$ for PBT$\mathrm{PCN}$ and $93 \mathrm{kcal} / \mathrm{mol}$ and $306 \mathrm{kcal} / \mathrm{mol}$ for Nylon6-PCN. Inspite of the higher interaction energies between polymer and modifier in PBT-PCN system than the Nylon6-PCN

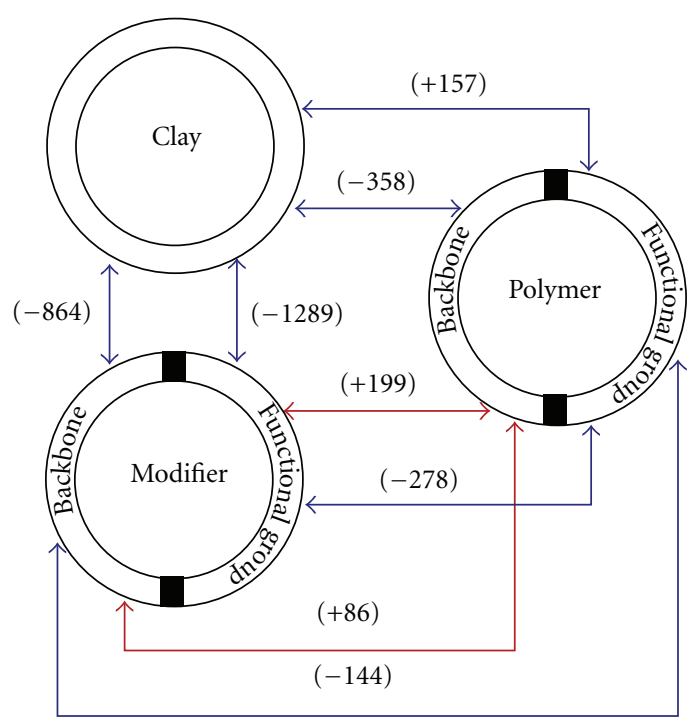

Figure 14: Energy map of PBT-PCN system.

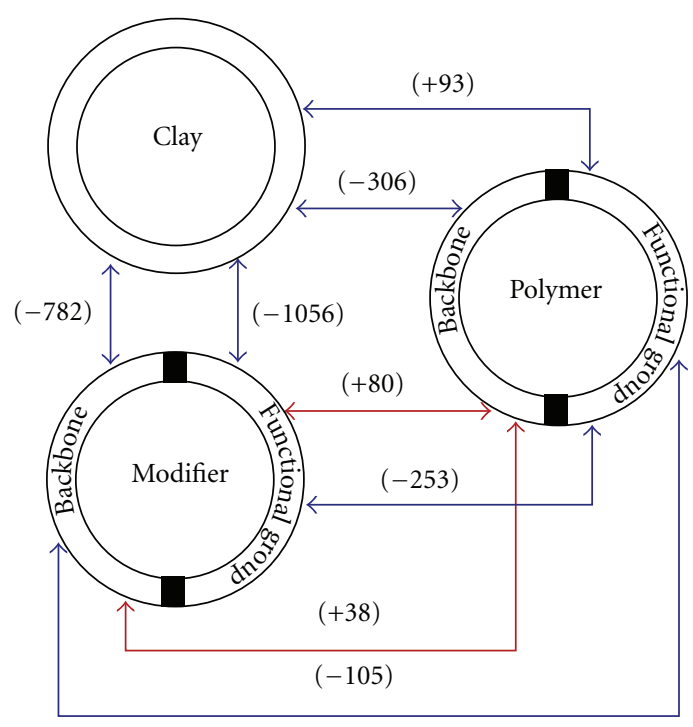

FIGURE 15: Energy map of nylon6-PCN system.

system, the alteration of crystallinity and improvement in mechanical properties is lower for PBT-PCN system. It appears that the initial crystallinity of the polymer may have affected the magnitude of interaction energy needed to alter the crystallinity and improve the mechanical properties of the PCN. The crystallinity of pure PBT is $35.6 \%$ while the crystallinity of Nylon6 is $27.6 \%$. Thus, it appears that significantly higher interaction energies between clay-modifier and polymer may be required to alter the crystallinity and improve mechanical properties of a polymer that is more crystalline to begin with. Modest differences are observed in the attractive interaction energies between the same modifier and clay in the presence of different polymers. 


\section{Conclusions}

A comprehensive assessment of PBT-PCN and Nylon6PCN systems using molecular dynamics and experimental techniques has been conducted. Experimental results and interaction energy maps of PBT-PCN system indicate that the underlying mechanisms of change in crystallinity and improvement in mechanical properties as proposed by altered phase theory are valid. Although the same amount of modified clay is used in the preparation of PCN with PBT and Nylon6, a dramatic difference in change in crystallinity and improvement in mechanical properties is observed. It appears that a polymer with higher crystallinity could require significantly higher attractive and repulsive interaction energies between the polymer and modifier compared to a polymer with lower crystallinity to achieve similar magnitude of percent change in crystallinity and improvement in mechanical properties of PCN.

\section{Acknowledgments}

The authors acknowledge the support of NSF-EPSCoR FlexEM grant for the work conducted. The authors also acknowledge the computational resources provided by the NDSU Center for high performance computing. The nanoindentation and spectroscopy instruments were obtained from NSF grant \#0315513 and 0320657.

\section{References}

[1] D. Sikdar, S. M. Pradhan, D. R. Katti, K. S. Katti, and B. Mohanty, "Altered phase model for polymer-clay nanocomposites," Langmuir, vol. 24, no. 10, pp. 5599-5607, 2008.

[2] J. Bandyopadhyay and S. Sinha Ray, "The quantitative analysis of nano-clay dispersion in polymer nanocomposites by small angle X-ray scattering combined with electron microscopy," Polymer, vol. 51, no. 6, pp. 1437-1449, 2010.

[3] E. P. Giannelis, "Polymer layered silicate nanocomposites," Advanced Materials, vol. 8, no. 1, pp. 29-35, 1996.

[4] A. K. Barick and D. K. Tripathy, "Effect of organoclay on the morphology, mechanical, thermal, and rheological properties of organophilic montmorillonite nanoclay based thermoplastic polyurethane nanocomposites prepared by melt blending," Polymer Engineering and Science, vol. 50, no. 3, pp. 484-498, 2010.

[5] Y. Wang, J. Gao, Y. Ma, and U. S. Agarwal, "Study on mechanical properties, thermal stability and crystallization behavior of PET/MMT nanocomposites," Composites B, vol. 37, no. 6, pp. 399-407, 2006.

[6] W. S. Chow, "Cyclic extrusion of poly(butylene terephthalate)/organo-montmorillonite nanocomposites: thermal and mechanical retention properties," Journal of Applied Polymer Science, vol. 110, no. 3, pp. 1642-1648, 2008.

[7] R. Herrera Alonso, L. Estevez, H. Lian, A. Kelarakis, and E. P. Giannelis, "Nafion-clay nanocomposite membranes: morphology and properties," Polymer, vol. 50, no. 11, pp. 2402-2410, 2009.

[8] E. Burgaz, H. Lian, R. H. Alonso, L. Estevez, A. Kelarakis, and E. P. Giannelis, "Nafion-clay hybrids with a network structure," Polymer, vol. 50, no. 11, pp. 2384-2392, 2009.
[9] S. C. Lao, C. Wu, T. J. Moon et al., "Flame-retardant polyamide 11 and 12 nanocomposites: thermal and flammability properties," Journal of Composite Materials, vol. 43, no. 17, pp. 18031818, 2009.

[10] D. Sikdar, D. Katti, K. Katti, and B. Mohanty, "Effect of organic modifiers on dynamic and static nanomechanical properties and crystallinity of intercalated clay-polycaprolactam nanocomposites," Journal of Applied Polymer Science, vol. 105, no. 2, pp. 790-802, 2007.

[11] D. Sikdar, D. R. Katti, K. S. Katti, and B. Mohanty, "Influence of backbone chain length and functional groups of organic modifiers on crystallinity and nanomechanical properties of intercalated clay-polycaprolactam nanocomposites," International Journal of Nanotechnology, vol. 6, no. 5-6, pp. 468-492, 2009.

[12] D. Sikdar, K. S. Katti, and D. R. Katti, "Molecular interactions alter clay and polymer structure in polymer clay nanocomposites," Journal of Nanoscience and Nanotechnology, vol. 8, no. 4, pp. 1638-1657, 2008.

[13] J. Xiao, Y. Hu, Z. Wang, Y. Tang, Z. Chen, and W. Fan, "Preparation and characterization of poly(butylene terephthalate) nanocomposites from thermally stable organic-modified montmorillonite," European Polymer Journal, vol. 41, no. 5, pp. 1030-1035, 2005.

[14] J. H. Chang, Y. U. An, S. J. Kim, and S. Im, "Poly(butylene terephthalate)/organoclay nanocomposites prepared by in situ interlayer polymerization and its fiber (II)," Polymer, vol. 44, no. 19, pp. 5655-5661, 2003.

[15] F. Wu and G. Yang, "Poly(butylene terephthalate)/organoclay nanocomposites prepared by in-situ bulk polymerization with cyclic poly(butylene terephthalate)," Materials Letters, vol. 63, no. 20, pp. 1686-1688, 2009.

[16] Y. W. Chang, S. Kim, and Y. Kyung, "Poly(butylene terephthalate)-clay nanocomposites prepared by melt intercalation: morphology and thermomechanical properties," Polymer International, vol. 54, no. 2, pp. 348-353, 2005.

[17] C. W. Shyang, "Tensile and thermal properties of poly(Butylene Terephtalate)/organo-montmorillonite nanocomposites," Malaysian Polymer Journal, vol. 3, pp. 1-13, 2008.

[18] Y. Hong, H. G. Yoon, and S. Lim, "Preparation of PBT/clay nanocomposites using supercritical process," International Journal of Precision Engineering and Manufacturing, vol. 10, no. 3, pp. 115-118, 2009.

[19] B. Mu, Q. Wang, T. Wang, H. Wang, L. Jian, and X. Pei, "preparation and friction properties of PBT/MMT composites," Polymer Composites, vol. 30, no. 5, pp. 619-628, 2009.

[20] A. B. Nirukhe and V. V. Shertukde, "Preparation and characterization of poly(butylene terephthalate) Nanocomposites with various organoclays," Journal of Applied Polymer Science, vol. 113, no. 1, pp. 585-592, 2009.

[21] D. Acierno, P. Scarfato, E. Amendola, G. Nocerino, and G. Costa, "Preparation and characterization of PBT nanocomposites compounded with different montmorillonites," Polymer Engineering and Science, vol. 44, no. 6, pp. 1012-1018, 2004.

[22] C. Wan, X. Bao, F. Zhao, B. Kandasubramanian, and M. P. Duggan, "Morphology and properties of silane-modified montmorillonite clays and clay/PBT composites," Journal of Applied Polymer Science, vol. 110, no. 1, pp. 550-557, 2008.

[23] D. Wu, C. Zhou, W. Yu, and X. Fan, "Effect of flocculated structure on rheology of poly(butylene terephthalate)/clay 
nanocomposites," Journal of Polymer Science B, vol. 43, no. 19, pp. 2807-2818, 2005.

[24] D. Sikdar, D. R. Katti, and K. S. Katti, "The role of interfacial interactions on the crystallinity and nanomechanical properties of clay-polymer nanocomposites: a molecular dynamics study," Journal of Applied Polymer Science, vol. 107, no. 5, pp. 3137-3148, 2008.

[25] D. Sikdar, D. R. Katti, and K. S. Katti, "A molecular model for $\varepsilon$-caprolactam-based intercalated polymer clay nanocomposite: integrating modeling and experiments," Langmuir, vol. 22, no. 18, pp. 7738-7747, 2006.

[26] K. S. Katti, D. Sikdar, D. R. Katti, P. Ghosh, and D. Verma, "Molecular interactions in intercalated organically modified clay and clay-polycaprolactam nanocomposites: experiments and modeling," Polymer, vol. 47, no. 1, pp. 403-414, 2006.

[27] D. Sikdar, D. R. Katti, K. S. Katti, and R. Bhowmik, "Insight into molecular interactions between constituents in polymer clay nanocomposites," Polymer, vol. 47, no. 14, pp. 5196-5205, 2006.

[28] D. Sikdar, D. R. Katti, K. S. Katti, and R. Bhowmik, "Tailoring crystallinity and nanomechanical properties of clay polymer nanocomposites: a molecular dynamics study," International Journal for Multiscale Computational Engineering, vol. 8, no. 6, p. 561, 2010.

[29] M. Kwiatkowska, G. Broza, K. Schulte, and Z. Roslaniec, "The in-situ synthesis of polybutylene terephthalate/carbon nanotubes composites," Reviews on Advanced Materials Science, vol. 12, no. 2, pp. 154-159, 2006.

[30] T. Hatakeyama and F. X. Quinn, Thermal Analysis: Fundamentals and Applications to Polymer Science, John Wiley \& Sons, New York, NY, USA, 2nd edition, 1999.

[31] Y. Liu, Y. F. Wang, T. G. Gerasimov, K. H. Heffner, and J. P. Harmon, "Thermal analysis of novel underfill materials with optimum processing characteristics," Journal of Applied Polymer Science, vol. 98, no. 3, pp. 1300-1307, 2005.

[32] Y. Kong and J. N. Hay, "The measurement of the crystallinity of polymers by DSC," Polymer, vol. 43, no. 14, pp. 3873-3878, 2002.

[33] W. C. Oliver and G. M. Pharr, "An improved technique for determining hardness and elastic modulus using load and displacement sensing indentation experiments," Journal of Materials Research, vol. 7, no. 6, pp. 1564-1583, 1992.

[34] A. Flores, F. Ania, and F. J. Baltá-Calleja, "From the glassy state to ordered polymer structures: a microhardness study," Polymer, vol. 50, no. 3, pp. 729-746, 2009.

[35] A. I. Balabanovich, T. A. Zevaco, and W. Schnabel, "Fire retardance in poly(butylene terephthalate). The effects of red phosphorus and radiation-induced cross-links," Macromolecular Materials and Engineering, vol. 289, no. 2, pp. 181-190, 2004.

[36] F. Wang, X. Meng, X. Xu et al., "Inhibited transesterification of PET/PBT blends filled with silica nanoparticles during melt processing," Polymer Degradation and Stability, vol. 93, no. 8, pp. 1397-1404, 2008.

[37] N. Tomar and S. N. Maiti, "Thermal and crystallization properties of pbt/abas Blends," Journal of Applied Polymer Science, vol. 113, no. 3, pp. 1657-1663, 2009.

[38] G. Socrates, Infrared and Raman Characteristic Group Frequencies: Tables and Charts, John Wiley \& Sons, Chichester, UK, 3rd edition, 2004.

[39] M. Ziari, O. van Asselen, M. Jansen, H. Goossens, and P. Schoenmakers, "An FTIR study on the solid-state copolymerization of bis(2-hydroxyethyl) terephthalate and poly(butylene terephthalate) and the resulting copolymers," Macromolecular Symposia, vol. 265, no. 1, pp. 290-296, 2008.

[40] Z. Yao, M. Lin, J. Zhou, H. Wang, W. Zhong, and Q. $\mathrm{Du}$, "Influence of epoxy resin on the morphological and rheological properties of PBT/ABS blends compatibilized by ASMA," Polymer Engineering and Science, vol. 47, no. 11, pp. 1943-1950, 2007.

[41] B. R. Brooks, R. E. Bruccoleri, B. D. Olafson, D. J. States, S. Swaminathan, and M. Karplus, "CHARMM-a program for macromolecular energy, minimization, and dynamics calculations," Journal of Computational Chemistry, vol. 4, pp. 187-217, 1983.

[42] D. R. Katti, S. R. Schmidt, P. Ghosh, and K. S. Katti, “Molecular modeling of the mechanical behavior and interactions in dry and slightly hydrated sodium montmorillonite interlayer," Canadian Geotechnical Journal, vol. 44, no. 4, pp. 425-435, 2007.

[43] S. R. Schmidt, D. R. Katti, P. Ghosh, and K. S. Katti, "Evolution of mechanical response of sodium montmorillonite interlayer with increasing hydration by molecular dynamics," Langmuir, vol. 21, no. 17, pp. 8069-8076, 2005.

[44] D. R. Katti, S. R. Schmidt, P. Ghosh, and K. S. Katti, "Modeling the response of pyrophyllite interlayer to applied stress using steered molecular dynamics," Clays and Clay Minerals, vol. 53, no. 2, pp. 171-178, 2005.

[45] E. R. Cruz-Chu, T. Ritz, Z. S. Siwy, and K. Schulten, "Molecular control of ionic conduction in polymer nanopores," Faraday Discussions, vol. 143, pp. 47-62, 2009.

[46] J. C. Phillips, R. Braun, W. Wang et al., "Scalable molecular dynamics with NAMD," Journal of Computational Chemistry, vol. 26, no. 16, pp. 1781-1802, 2005.

[47] W. Humphrey, A. Dalke, and K. Schulten, "VMD: visual molecular dynamics," Journal of Molecular Graphics, vol. 14, no. 1, pp. 33-38, 1996.

[48] M. Fermeglia, M. Ferrone, and S. Pricl, "Estimation of the binding energy in random poly butylene terephtalate-cothiodiethylene terephtalate copolyesters/clay nanocomposites via molecular simulation," Molecular Simulation, vol. 30, no. 5, pp. 289-300, 2004. 

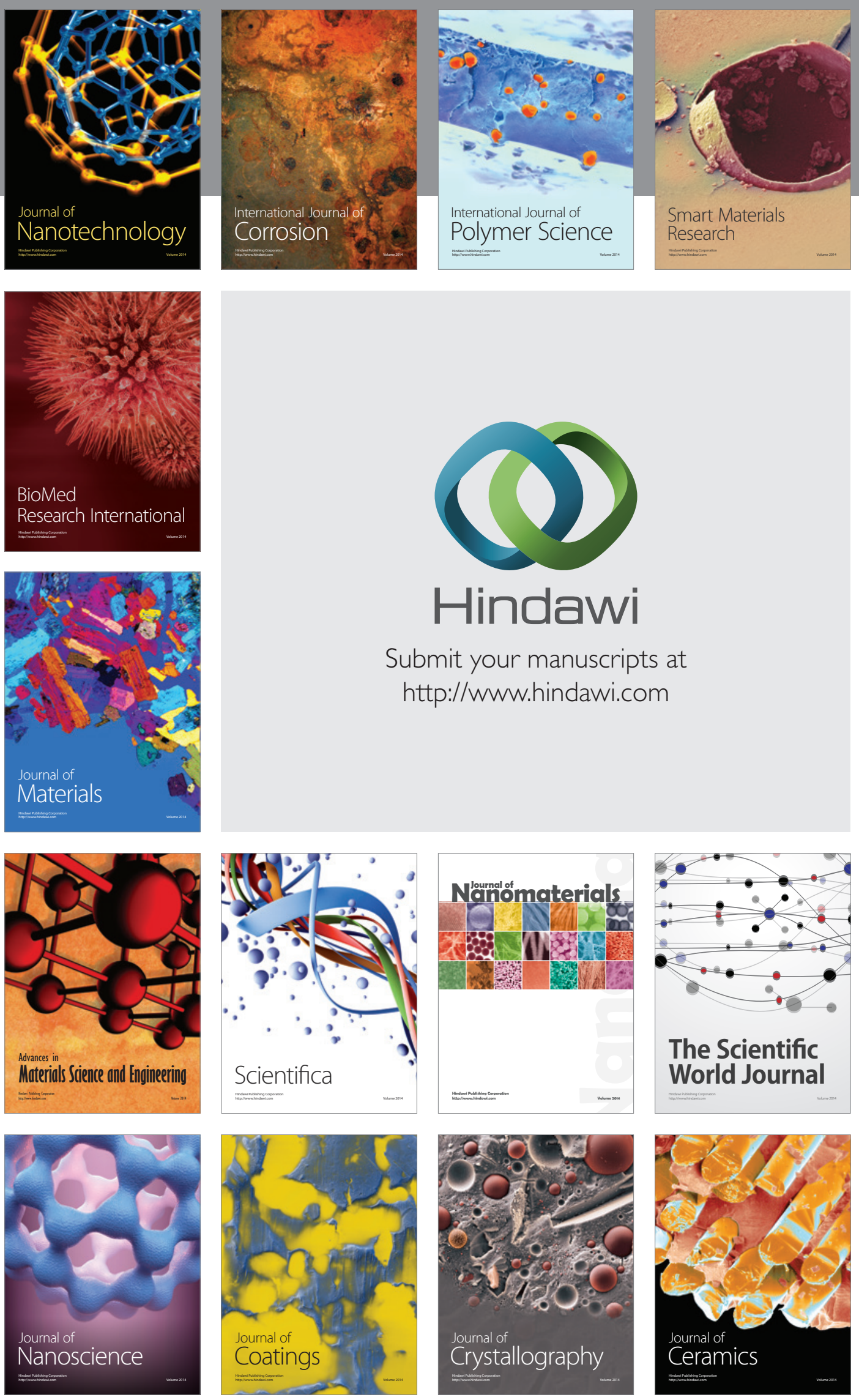

The Scientific World Journal

Submit your manuscripts at

http://www.hindawi.com

\section{World Journal}

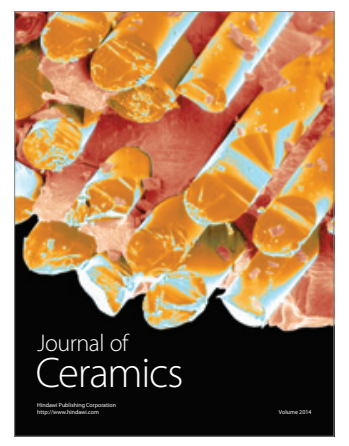

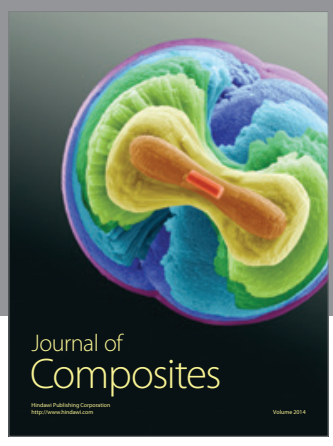
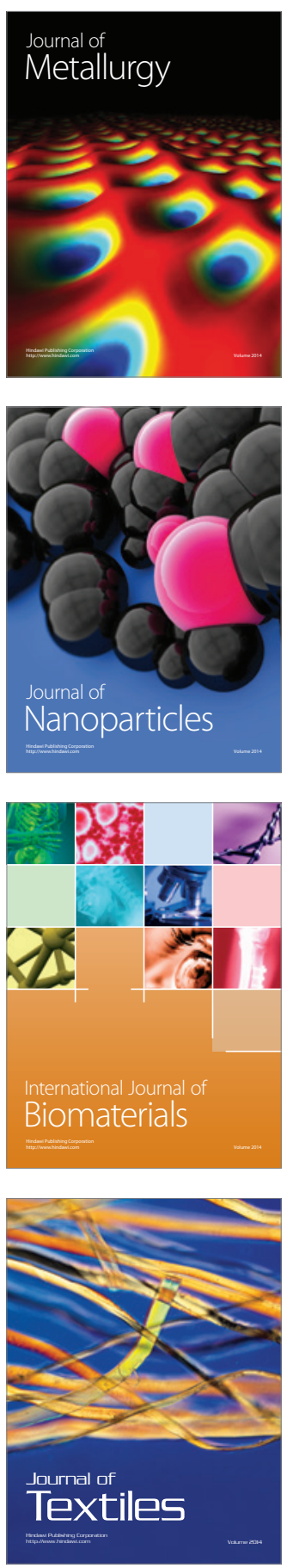